\title{
Intrathecal Methotrexate Regimen
}

National Cancer Institute

\section{Source}

National Cancer Institute. Intrathecal Methotrexate Regimen. NCI Thesaurus. Code

C160066.

A chemotherapy regimen consisting of intrathecal methotrexate that may be used in the treatment of acute lymphoblastic, chronic lymphocytic and acute myeloid leukemias; and diffuse large B-cell and small lymphocytic lymphomas, with central nervous system (CNS) involvement. 